American Journal of Nursing Science
2016; 5(5): $175-184$
http://www.sciencepublishinggroup.com/j/ajns
doi: $10.11648 /$ j.ajns.20160505.12
ISSN: 2328 -5745 (Print); ISSN: $2328-5753$ (Online)

\title{
Cervical Cancer and Screening Test (PAP Test): Knowledge and Beliefs of Egyptian Women
}

\author{
Sahar M. Yakout ${ }^{1}$, Salma Moawed ${ }^{2}$, Essmat M. Gemeay ${ }^{3}$ \\ ${ }^{1}$ Obstetric and Gynaecological Nursing, Faculty of Nursing, Alexandria University, Alexandria, Egypt \\ ${ }^{2}$ Maternal and child health Nursing Department, Faculty of Nursing, King Saud University, Riyadh, Saudi Arabia \\ ${ }^{3}$ Psychiatric and Mental Health Nursing Department, Faculty of Nursing, Tanta University, Cairo, Egypt
}

Email address:

szamzam@ksu.edu.sa (S. M. Yakout)

\section{To cite this article:}

Sahar M. Yakout, Salma Moawed, Essmat M. Gemeay. Cervical Cancer and Screening Test (PAP Test): Knowledge and Beliefs of Egyptian Women. American Journal of Nursing Science. Vol. 5, No. 5, 2016, pp. 175-184. doi: 10.11648/j.ajns.20160505.12

Received: July 30, 2016; Accepted: August 10, 2016; Published: September 5, 2016

\begin{abstract}
Cervical cancer is the fourth most common cancer in women, and the seventh overall, with an estimated 528,000 new cases in 2012. In Egypt the incidence of cervical cancer is 866 per year where mortality rate is 373 per year. The current study aims to determine women's beliefs and knowledge towards cervical cancer and Pap smear. The study was conducted at the outpatient obstetrics clinics of two hospitals namely El- Mainshawy health insurance Hospital, and El - Aiada El- Shamela at Tanta governorate. The study subjects comprised 1000 women attending the above mentioned settings two tools were used: An interview assessment sheet and the Health Believe Model (HBM). Results of the current study illustrated that Out of the 1,000 women interviewed, $(68.0 \%)$ could know the definition of cervical cancer and related to a virus as its causative agent. About $95 \%$ of the women did not have an idea of the risk factors for cervical cancer, the knowledge about Pap test is quite poor, only $13.3 \%$ identify Pap smear test while $86.7 \%$ had no idea at all. In terms of the perceived benefits of Pap test, about $50.3 \%$ of the participants believed that Pap tests are the best way to detect cervical cancer, $42.9 \%$ believed that cervical cancer can be cured easily if detected early, and $62 \%$ disagree that a Pap test is important for save their health. The present study concluded that inefficient utilization of cervical cancer and its screening test would be affected by poor knowledge and negative beliefs related to cervical cancer screening in women. It was recommended that development of effective intervention programs strategies for Egyptian women and identify those women who are most at risk for cervical cancer and would benefit from intervention programs to increase cervical cancer screening rates.
\end{abstract}

Keywords: Knowledge, Beliefs, HBM, Papanicolaou Smear (Pap Smear), Benefits, Perceived Risk, Cervical Cancer

\section{Introduction}

Cervical cancer is the fourth most common cancer in women, and the seventh overall, with an estimated 528,000 new cases in 2012 worldwide [1]. About half a million new cases are seen worldwide each year, most occurring in developing countries [2]. In Egypt the incidence of cervical cancer is 866 per year where mortality rate is 373 per year [3].

Cancer of the cervix is the commonest genital tract malignancy in the female [4]. Cervical cancer has positive association with infection of human papillomavirus (HPV), and repeated or persistent HPV infections appear to raise the chances of developing the disease [5]. Tobacco smoking, high parity, long-term hormonal contraceptive use, coinfection with Chlamydia trachomatis, herpes simplex virus type 2, HIV, immunosuppression, certain dietary deficiencies, and genetic and immunological host factors are contributing factors to cervical cancers [6].

The availability of effective prophylactic HPV vaccines gives new promise for a primary prevention strategy for HPV infection and cervical cancer [7]. However, the current vaccines only protect against $70 \%$ of the disease, and are only effective for those not yet exposed to the virus.

Cervical cancer incidence and mortality have declined substantially in western countries following the introduction of screening programmes. Screening programmes in Africa are however often rudimentary or nonexistent. The screening techniques often used are Pap smear test [8]. 
The Papanicolaou smear is a reliable, inexpensive and effective screening test for cervical cancer [9, 10]. For a long time, the Papanicolaou smear (Pap smear) has been considered the most helpful test used for detecting cervical lesions at early stage [11]. Due to the high effectiveness of this preventive screening, women's incidence of invasive cervical cancer has substantially decreased. However, the greatest part of women who die from cervical cancer are in general those who have never had history of previous Pap smear uptake, or who have long intervals between Pap screenings [12, 13]. Needs assessment in any society is essential to any plan to promote health behavior in this area [14]. Therefore, it is important to not only study of the direct risk factors for cervical cancer that predominate in different subpopulations of women, but also of the cognitive, emotional, and environmental aspects that might influence women's decision to participate actively in preventive screening programs. So, Health Belief Model (HBM) has been considered to be one of the most representative ones due to its effectiveness in explaining change and maintenance of health behavior [15].

The Health belief model was originally developed in the 1950 s by a social psychologist in the United Station public Health Service to explain the widespread failure of people to participate in programs to prevent and detect disease. Later, the model was extended to study peoples' responses to symptoms and their behaviors in response to diagnosed illness, specially adherence to medical regimens [16]. This model aims to explain preventive health behaviors rather than behaviors in time of illness [17]. Major health behaviors emphasized by the Health Belief Model focus on prevention exposure of diseases at their asymptomatic stage [18]. For example, as delineated by the Health Belief Model (HBM) [19]. the likelihood that an individual will take action to prevent or detect disease is determined by several factors: perceived vulnerability to the health condition, perceived severity of the health threat, perceived benefits of performing the health behavior, and perceived costs and barriers of performing this behavior [19]. Later on, selfefficacy was added to HBM to measure the belief in one's own ability to perform a certain behavior [20]. The HBM was originally developed as a systematic method to explain and predict preventive health behaviors and is still one of the most widely used conceptual frameworks of health behavior [21].

Maternity nurse have an opportunity to affect the incidence and mortality of cervical cancer by improving screening practices of women. While preparing their initiations, it is extremely important for nurses to know the knowledge level and health beliefs of the women living in the region in order to improve their participation in cervical cancer screening and increase their benefiting from the services offered. At the same time, this information may help in planning nursing initiatives that are created to support and encourage women at the first step to improve their participation in cervical cancer screening. Currently, education of women is focused on in programs carried out to increase the participation of women in cervical cancer screening education. In studies on the efficiency of training shown that culturally specific educational programs are more effective for raising the level of knowledge and correcting the wrong information $[22,23,24,25]$. Accurate health care information and communication by health providers are importance to gain the true knowledge and the health behaviors and to change the false beliefs. Therefore, maternity nurse need to address the knowledge and beliefs of the women about cervical cancer and its screening test.

The Health Belief Model Scale for Cervical Cancer and the Pap Smear Test was found to be a valid and reliable tool in assessing the women's health beliefs. Understanding the beliefs of women in respect of cervical cancer and the Pap smear test will help healthcare professionals to develop more effective cervical cancer screening programs.

\subsection{Aim of the Study}

This study aimed to assess women's knowledge and beliefs toward cervical cancer and screening test (PAP) in Egypt.

\subsection{Research Questions}

1. Did the Egyptian women have knowledge about cervical cancer and PAP smear test.

2. What are their beliefs about cervical cancer in general and screening test (PAP smear) in particular.

3. Is there any relationship between socio-demographic characteristics of women and their level of knowledge about cervical cancer and screening test (PAP Smear).

\subsection{Conceptual Definition}

Perceived susceptibility: The degree to which an individual feels personally susceptible to contracting a condition. Perceived severity: The degree to which an individual values the condition as serious; through emotional arousal or consideration of the consequences of the condition. Perceived benefits: The degree to which an individual believes that taking a specific action to prevent a condition will be beneficial and effective. Perceived barriers: The degree to which negative aspects of an action serve as barriers to action, causing avoidance. Cues to action: Triggers that prompt an individual to action. [26]

\section{Subjects and Method}

\subsection{Study Design and Setting}

Descriptive exploratory cross sectional and correlation design was used. This study, carried out on two hospital in Egypt namely El- Mainshawy health insurance Hospital, and El - Aiada El- Shamela at Tanta governorate at the outpatient clinics of the gynecology and obstetrics departments of the hospitals. These setting serve a large number of population free. 


\subsection{Subject}

Convenient sample of (1000) women who agreed to participate in this study.

\subsection{Tools}

Data of this study was collected using the following two tools:

Tool 1. Structured Interviewing Questionnaire (SIQ) was developed by the researchers based on literature review, it included two parts:

Part I: Socio-demographic characteristics such as age, level of education, marital relation, duration of marriage, number of children, smoking and family history of cervical cancer.

Part II: to assess knowledge of subjects about Pap test, HPV vaccine and cervical cancer

Tool II: Health Belief Model Scale for Cervical Cancer and Pap Smear Test. It was used to determine women's beliefs regarding cervical cancer and its screening. This scale was adapting from Champion's Breast Health Survey [27, 28], Ackerson K, Gretebeck K [29]. and Akyüz A, Güvenç $\mathrm{G}$, Yavan $T$, et al [30]. which specifies five motivational cognitions (perceived susceptibility, Perceived severity, Perceived benefits, Perceived barriers and cues to action)

\subsection{Validity and Reliability}

Content validity of the questionnaire was determined using the comments of eight experts including gynecologists and midwifery faculty members and its reliability using test-retest. Cronbach's alpha coefficients ranged from 0.84 (perceived severity) to 0.98 (cues to action), indicating that each subscale had good internal consistency. All test-retest correlations were greater than 0.90 and significant at the 0.01 level.

\subsection{Administrative Design}

An official permission was obtained from the concerned departments to conduct the proposed study. Once permission was granted to proceed with the proposed study, the data was collected via face-to-face interviews by one trained interviewer using a structured questionnaire.

\subsection{Pilot Study}

In preliminary work; the items were translated into Arabic to be appropriate for Arab language The study tools were pre-tested on a random sample of 100 women $(10 \%)$ selected from the same study setting to check the clarity, applicability, any difficulties with their application, and to determine the time needed for completion of the tools. Modification of the tools was done according to the pilot study results. Subjects who shared in the pilot study were excluded from the study subjects.

\subsection{Procedure}

- The aim of this phase was to collect data about women to determine those who have knowledge and to explore their beliefs using tool I \&II.

-Subjects who agreed to participate in the study, the researchers introduced themselves to the respondents, and explained the aim and objectives of the study to them in the study settings.

-Then, they were individually interviewed by the researcher to complete the basic data using an Interviewing Assessment Sheet.

- Each questionnaire was semi-structured, consisting of 20 questions. The first 9 questions on the questionnaire gathered background information on the participant. The next 11 questions were divided into those assessing the participant knowledge regarding cervical cancer and its screening test (Pap), including table $(2,3,4)$. After the completion of the last 11 questions, women were interviewed to assess their beliefs according to the following; perceived benefits was assessed using five items, perceived severity was assessed using six items and perceived barriers was assessed using nineteen items. Beliefs of the studied women about Perceived susceptibility to acquire cervical cancer or to have an abnormal Pap test was assessed using 10 items. Beliefs of the studied women about cues to action that cause that women take the Pap test was assessed using twelve items

- The time taken for every questionnaire to be completed was about 20-30 minutes for each subject.

- The study was conducted throughout a period of six months from March 2015 to the end of August 2015

\subsection{Ethical Consideration}

Before the beginning of the study, an informed oral consent was taken from the women after explaining the aim of the study. The participants were assured of the confidentiality of their personal information. Women were allowed to withdraw from the study at any time.

\subsection{Statistical Analysis}

SPSS ver.17 for data analysis. $\mathrm{F}$ test (ANOVA) Statistically significant at $\mathrm{p} \leq 0.05$, student t-test statistically significant at $p \leq 0.05$ and $\chi^{2}$ : Chi square test; MC: Monte Carlo for Chi square test significant at $\mathrm{p} \leq 0.05$

-HBM model scale: The following provides a description of each item within each subscale measured in our study. Responses to each item was scored on a four-point Likerttype scale ranging from 1 (strongly disagree) to 4 (strongly agree). the scores were summed and then were converted to 0-100 to make the total scores more informative. Higher score reflects a higher or better beliefs about Pap smear. Beliefs score was classified into 0-50 "negative beliefs" and 50 and upper "positive beliefs".

-Knowledge questions had two options. To calculate knowledge scores, correct answers was given score 1 and incorrect answers will be given score 0 . The scores was summed and then were converted to $0-100$ to make the total scores more informative. Higher score reflects a higher knowledge about cervical cancer and its Pap smear. Total 
knowledge score was classified into three level; scores 0-33.3 "low", scores of 33.4-66.6 level of "moderate" and a score of 66.7 or higher level of "high".

\section{Results}

Table 1. Socio-demographic characteristics of studied women $(n=1000)$.

\begin{tabular}{|c|c|c|}
\hline Variables & No. & $\%$ \\
\hline \multicolumn{3}{|l|}{ 1- Age (years) } \\
\hline$<20$ & 280 & 28.0 \\
\hline $20-<30$ & 586 & 58.6 \\
\hline $30-<40$ & 110 & 11.0 \\
\hline $40-<50$ & 14 & 1.4 \\
\hline$\geq 50$ & 10 & 1.0 \\
\hline \multicolumn{3}{|l|}{ 2- Marital status } \\
\hline Married & 751 & 75.1 \\
\hline Divorced & 188 & 18.8 \\
\hline Single & 51 & 5.1 \\
\hline Widow & 10 & 1.0 \\
\hline \multicolumn{3}{|l|}{ 3- Level of education } \\
\hline Illiterate & 122 & 12.2 \\
\hline Read and write & 127 & 12.7 \\
\hline Primary education & 264 & 26.4 \\
\hline Secondary education & 224 & 22.4 \\
\hline University or higher & 263 & 26.3 \\
\hline \multicolumn{3}{|l|}{ 4- number of children } \\
\hline None & 694 & 69.4 \\
\hline One child & 96 & 9.6 \\
\hline 2 or 3 children & 140 & 14.0 \\
\hline 4 or 5 children & 68 & 6.8 \\
\hline 6 or more children & 2 & 0.2 \\
\hline \multicolumn{3}{|l|}{ 5- Duration of marriage } \\
\hline Unmarried & 51 & 5.1 \\
\hline 1 year & 185 & 18.5 \\
\hline $2-3$ years & 137 & 13.7 \\
\hline 3 to less than 6 years & 127 & 12.7 \\
\hline 6 to less than 10 years & 239 & 23.9 \\
\hline More than 10 years & 261 & 26.1 \\
\hline \multicolumn{3}{|l|}{ 6- Smoking } \\
\hline Yes & 53 & 5.3 \\
\hline No & 947 & 94.7 \\
\hline \multicolumn{3}{|l|}{ 7- Passive smoke } \\
\hline Yes & 762 & 76.2 \\
\hline No & 238 & 23.8 \\
\hline \multicolumn{3}{|c|}{ 8- Family history cervical cancer } \\
\hline Yes & 171 & 17.1 \\
\hline No & 829 & 82.9 \\
\hline
\end{tabular}

Regarding (Table 1) socio-demographic characteristics of the studied subjects, $58.6 \%$ women aged between 20 to less than 30 years, $12.7 \%$ were read and write while 26.4 had primary education and $26.3 \%$ had a university education, $5.1 \%$ single while $81.9 \%$ were ranged from divorced, married and widow, 23.9 married for less than 10 years, $69.4 \%$ had no children, $94.7 \%$ nonsmokers but 76.2 were passive smokers and most $(82.9 \%)$ had no history of cervical cancer while 17.1 had history.
Table 2. Knowledge of studied women about Pap smear as screening test $(n=1000)$.

\begin{tabular}{lll}
\hline Variables & No. & $\%$ \\
\hline Did you know Pap test? & 133 & \\
Known & 887 & 13.3 \\
Not known & & 88.7 \\
*Reasons not doing pap smear & 887 & \\
Do not know & 189 & 88.7 \\
Fear of vaginal examination & 70 & 18.9 \\
Sense of modesty & 408 & 7.0 \\
Absence of symptoms & 176 & 40.8 \\
Lack of interest & 451 & 17.6 \\
My doctor did not ask me to do this & & 45.1 \\
examination & 51 & 5.1 \\
Not married & & \\
\hline *more than one answer & &
\end{tabular}

Less than one quarter $(13.3 \%)$ of the 1,000 women had known a Pap screening while the majority $(88.7 \%)$ not know. The major reason by the women who had not done Pap test was lack of awareness as noted by $88.7 \%$. The other reasons were fear of vaginal examination $(18.9 \%)$ lack of interest $(17.6 \%)$, absence of symptoms $(40.8 \%)$, or the doctor did not requested for her $(45.1 \%)$. Table (2)

Table 3. Knowledge of studied women about HPV vaccine $(n=1000)$.

\begin{tabular}{lll}
\hline Variables & No. & \% \\
\hline 24- Did you take HPV vaccine? & 199 & 19.9 \\
Yes & 801 & 80.1 \\
No & & \\
25- If answer no, why? $(\mathrm{n}=801)$ & 667 & 83.3 \\
I do not know anything about the vaccine & 22 & 2.7 \\
Because it is expensive & 71 & 8.9 \\
Fear of infection as a result of this vaccination & 41 & 5.1 \\
Refused to parents or husband & \\
\hline
\end{tabular}

Regarding Table (3), the majority $(80.1 \%)$ of the study subjects did not take HPV vaccine because the majority $(83.3 \%)$ they do not know it while about one fifth $(19.9 \%)$ of them take the vaccine. The other reasons were fear of infection $(8.9 \%)$, expensive $(2.7 \%)$ and refused from parents or husband $(5.1 \%)$.

Table 4. Proportion of correct answers to knowledge questions about cervical cancer and PAP screening test $(n=1000)$.

\begin{tabular}{lll}
\hline & \multicolumn{2}{l}{ Correct answer } \\
\hline Variables & No. & $\%$ \\
Identification the definition of cervical cancer? & 680 & 68.0 \\
Identification of cervical cancer lead to death & 89 & 8.9 \\
Identification of risk Factors lead to cervical cancer & 58 & 5.8 \\
Identification of symptoms of cervical cancer & 78 & 7.8 \\
Identification of prevention of cervical cancer & 50 & 5.0 \\
$\begin{array}{l}\text { Identification of pap smear or test? } \\
\text { Identification that affected person can recover from }\end{array}$ & 133 & 13.3 \\
$\begin{array}{l}\text { cervical cancer? } \\
\text { Identification that early detection of cervical cancer, }\end{array}$ & 83 & 8.3 \\
more effect of treatment? & 504 & 50.4 \\
\hline
\end{tabular}

According to Table (4). Out of the 1,000 women interviewed, only $(68.0 \%)$ could know the definition of cervical cancer but not known its causative agent. About $95 \%$ of the women did not have an idea of the risk factors for 
cervical cancer and they suggested due to evil eye, and poor hygiene as the cause. So, $94.2 \%$ were unable to correctly identify that family history, cigarette smoking, hormonal contraception usage, poor diet and HIV/AIDS as risk factors for cervical cancer. They were minority $(7.8 \%)$ able to identify the symptoms of cervical cancer. Only $5 \%$ of the women could identify screening and vaccination as ways to prevent cervical cancer. The knowledge about pap test is quite poor, only $13.3 \%$ identify PAP smear test while $86.7 \%$ had no idea at all. Eighty three $(8.3 \%)$ of the 1,000 women answered correctly that affected person can recover from cervical cancer.
Table 5. Knowledge of studied women about cervical cancer and its screening test $(n=1000)$.

\begin{tabular}{lll}
\hline & No. & $\%$ \\
\hline Low $(<33.3 \%)$ & 842 & 84.2 \\
Moderate $(33.33-66.6 \%)$ & 123 & 12.3 \\
High $(>66.6 \%)$ & 35 & 3.5 \\
\hline
\end{tabular}

Regarding table (5), it was noticed that the majority $(84.2 \%)$ of the study subjects had low level of knowledge about cervical cancer and its screening test while a minority $(3.5 \%)$ had higher level of knowledge.

Table 6. Beliefs of the studied women about the perceived benefits, severity and barriers to take PAP test to reduce risk of cervical cancer ( $n=1000)$.

\begin{tabular}{|c|c|c|c|c|c|c|c|c|}
\hline & \multicolumn{2}{|c|}{ Strongly agree } & \multicolumn{2}{|c|}{ Agree } & \multicolumn{2}{|c|}{ Disagree } & \multicolumn{2}{|c|}{ Strongly disagree } \\
\hline & No. & $\%$ & No. & $\%$ & No. & $\%$ & No. & $\%$ \\
\hline \multicolumn{9}{|l|}{ Perceived Benefits } \\
\hline Pap test makes me feel good & 189 & 18.9 & 447 & 44.7 & 345 & 34.5 & 19 & 1.9 \\
\hline For early detection of cervical cancer & 86 & 8.6 & 531 & 53.1 & 356 & 35.6 & 27 & 2.7 \\
\hline Getting a Pap test is a good investment of my time in health & 107 & 10.7 & 461 & 46.1 & 409 & 40.9 & 23 & 2.3 \\
\hline A Pap test can find cervical cancer when it is possible to cure & 250 & 25.0 & 298 & 29.8 & 429 & 42.9 & 23 & 2.3 \\
\hline The Pap can save my life & 97 & 9.7 & 240 & 24.0 & 620 & 62.0 & 43 & 4.3 \\
\hline An abnormal pap test, Can lead to cervical cancer without treatment & 164 & 16.4 & 505 & 50.5 & 327 & 32.7 & 4 & 0.4 \\
\hline Not having a pap test, Can result a serious health problem & 154 & 15.4 & 559 & 55.9 & 274 & 27.4 & 13 & 1.3 \\
\hline Cervical cancer may Lead to death & 82 & 8.2 & 261 & 26.1 & 621 & 62.1 & 36 & 3.6 \\
\hline Cervical cancer may lead to Hysterectomy & 97 & 9.7 & 523 & 52.3 & 361 & 36.1 & 19 & 1.9 \\
\hline Cervical cancer is not a Serious health problem & 159 & 15.9 & 543 & 54.3 & 298 & 29.8 & 0 & 0.0 \\
\hline Cervical cancer can lead women to receive Chemotherapy & 178 & 17.8 & 341 & 34.1 & 481 & 48.1 & 0 & 0.0 \\
\hline \multicolumn{9}{|l|}{ Perceived Barriers } \\
\hline Move the intrauterine device & 34 & 3.4 & 170 & 17.0 & 776 & 77.6 & 20 & 2.0 \\
\hline Getting a pap test is painful & 18 & 1.8 & 317 & 31.7 & 629 & 62.9 & 36 & 3.6 \\
\hline Getting a Pap test only will give me problems & 79 & 7.9 & 457 & 45.7 & 383 & 38.3 & 81 & 8.1 \\
\hline Getting a Pap test is expensive & 18 & 1.8 & 235 & 23.5 & 710 & 71.0 & 37 & 3.7 \\
\hline Getting a Pap test is embarrassing & 20 & 2.0 & 301 & 30.1 & 676 & 67.6 & 3 & 0.3 \\
\hline I do not have information about it & 435 & 43.5 & 432 & 43.2 & 128 & 12.8 & 5 & 0.5 \\
\hline I prefer that a female gives me the Pap test & 300 & 30.0 & 469 & 46.9 & 211 & 21.1 & 20 & 2.0 \\
\hline I have not taken the Pap test because they treat me badly in the health center & 153 & 15.3 & 196 & 19.6 & 573 & 57.3 & 78 & 7.8 \\
\hline I do not know if I need to have a Pap test & 210 & 21.0 & 103 & 10.3 & 612 & 61.2 & 75 & 7.5 \\
\hline I do not know at what age & 260 & 26.0 & 384 & 38.4 & 352 & 35.2 & 4 & 0.4 \\
\hline I have not taken a Pap test because I need to wait a long time to seen & 138 & 13.8 & 233 & 23.3 & 612 & 61.2 & 17 & 1.7 \\
\hline My husband does want me to get a pap test & 48 & 4.8 & 207 & 20.7 & 728 & 72.8 & 17 & 1.7 \\
\hline Do not have money for transportation & 36 & 3.6 & 99 & 9.9 & 826 & 82.6 & 39 & 3.9 \\
\hline I am afraid to find out cervical cancer & 7 & 0.7 & 97 & 9.7 & 857 & 85.7 & 39 & 3.9 \\
\hline Health care center is only open during hours when I can not go & 0 & 0.0 & 127 & 12.7 & 820 & 82.0 & 53 & 5.3 \\
\hline Embarrassed to have genital exam & 116 & 11.6 & 187 & 18.7 & 665 & 66.5 & 32 & 3.2 \\
\hline
\end{tabular}

In terms of the perceived benefits of Pap test, about $50.3 \%$ of the participants believed that Pap tests are the best way to detect cervical cancer, $42.9 \%$ believed that cervical cancer cannot be cured easily if detected early, and $62 \%$ beliefs that a Pap test is not important for save my health.

With regard to the perceived severity variables, women who perceived severity, $62.1 \%$ of them disagree that Pap test decreases the chances of dying from cervical cancer. More than half $50.5 \%, 55.9 \%$ and $52.3 \% 54.3 \%$ agree that an abnormal pap test, can lead to cervical cancer without treatment, not having a pap test, can result a serious health problem, cervical cancer may lead to hysterectomy and Cervical cancer is not a Serious health problem respectively.
The participants experienced some access barriers to obtaining a Pap test. For example, some women believed that, they do not have information about it (43.5\%) and prefer that a female gives her the Pap test $(46.9 \%)$ believing that one's spouse would be uncomfortable with screening performed by a male doctor but the majority $(82.6 \%, 85.7 \%$, disagree about not have money for transportation or afraid to find out cervical cancer respectively. in addition, $67.7 \%$, $77.6 \%$ disagree that they do not have time to get a pap test or to move the intrauterine device respectively. $61.2 \%$, disagree that one does not need a test if feeling well, believing a test will be painful or unpleasant $(31.7 \%)$, and believing a Pap test will be embarrassing (30.1\%). as shown in Table (6). 
Table 7. Beliefs of the studied women about Perceived susceptibility to acquire cervical cancer or to have an abnormal Pap test (n-1000).

\begin{tabular}{|c|c|c|c|c|c|c|c|c|}
\hline & \multicolumn{2}{|c|}{ Strongly agree } & \multicolumn{2}{|c|}{ Agree } & \multicolumn{2}{|c|}{ Disagree } & \multicolumn{2}{|c|}{ Strongly disagree } \\
\hline & No. & $\%$ & No. & $\%$ & No. & $\%$ & No. & $\%$ \\
\hline I am not at risk for an abnormal pap test & 97 & 9.7 & 376 & 37.6 & 521 & 52.1 & 6 & 0.6 \\
\hline I have No symptoms & 190 & 19.0 & 377 & 37.7 & 368 & 36.8 & 65 & 6.5 \\
\hline I have No children & 172 & 17.2 & 370 & 37.0 & 358 & 35.8 & 100 & 10.0 \\
\hline Not married & 51 & 5.1 & - & - & 660 & 66.0 & 289 & 8.9 \\
\hline Not Pregnant & 156 & 15.6 & 231 & 23.1 & 543 & 54.3 & 70 & 7.0 \\
\hline I have Infertility no need for pap test & 137 & 13.7 & 144 & 14.4 & 707 & 70.7 & 12 & 1.2 \\
\hline If I have cervical cancer, I can die & 14 & 1.4 & 115 & 11.5 & 779 & 77.9 & 92 & 9.2 \\
\hline Cervical cancer is most common among women & 80 & 8.0 & 131 & 13.1 & 713 & 71.3 & 76 & 7.6 \\
\hline $\begin{array}{l}\text { I do not have history of cervical cancer in my } \\
\text { family,it is very unlikely to get }\end{array}$ & 113 & 11.3 & 247 & 24.7 & 623 & 62.3 & 17 & 1.7 \\
\hline
\end{tabular}

With regard to perceived risk in Table (7), 83.2\% of participants considered themselves at risk for developing cervical cancer and $37.7 \%$ agree that they have no symptoms so they not susceptible to acquire cervical cancer or to have an abnormal Pap test (52.1\%). The study subjects $(70.7 \%$,
$77.9 \%, 71.3 \%$, and $62.3 \%$ ) disagree that if they have Infertility no need for pap test, can die from cervical cancer, cervical cancer is most common among women and not have history of cervical cancer in their families. So, it is very unlikely to get respectively.

Table 8. Beliefs of the studied women about cues to action that cause that women take the Pap test $(n=1000)$.

\begin{tabular}{|c|c|c|c|c|c|c|c|c|}
\hline & \multicolumn{2}{|c|}{ Strongly agree } & \multicolumn{2}{|c|}{ Agree } & \multicolumn{2}{|c|}{ Disagree } & \multicolumn{2}{|c|}{ Strongly disagree } \\
\hline & No. & $\%$ & No. & $\%$ & No. & $\%$ & No. & $\%$ \\
\hline Take care of my health & 66 & 6.6 & 371 & 37.1 & 554 & 55.4 & 9 & 0.9 \\
\hline After hearing something about cervical cancer & 128 & 12.8 & 360 & 36.0 & 499 & 49.9 & 13 & 1.3 \\
\hline Mid wife tell me & 63 & 6.3 & 360 & 36.0 & 480 & 48.0 & 97 & 9.7 \\
\hline Doctor tell me & 78 & 7.8 & 295 & 29.5 & 488 & 48.8 & 139 & 13.9 \\
\hline Friend spoke to me & 52 & 5.2 & 182 & 18.2 & 627 & 62.7 & 139 & 13.9 \\
\hline My family told me to get & 20 & 2.0 & 144 & 14.4 & 694 & 69.4 & 142 & 14.2 \\
\hline I read something in Newspaper & 44 & 4.4 & 348 & 34.8 & 488 & 48.8 & 120 & 12.0 \\
\hline Because I have genital Bleeding & 95 & 9.5 & 469 & 46.9 & 307 & 30.7 & 129 & 12.9 \\
\hline Because I have Pain in genital area & 119 & 11.9 & 418 & 41.8 & 308 & 30.8 & 155 & 15.5 \\
\hline Because I had Discomfort in my genital area & 65 & 6.5 & 302 & 30.2 & 489 & 48.9 & 144 & 14.4 \\
\hline
\end{tabular}

Table (8) revealed that, Five hundred fifty four clients (55.4\%) disagree that Pap smear tests can take care of their health. About one half (41.8\%) and more than one half (46.9\%) agree that they had Pap smear tests if they had gynecological problems such as genital bleeding or pain respectively. Six hundred twenty seven clients (62.7\%) their believes ranged from disagree to strongly disagree that health care providers not made them aware of the importance of early detection of cervical cancer such as doctors.

Table 9. Total believes scores about cervical cancer and PAP screening test $(n=1000)$.

\begin{tabular}{|c|c|c|c|c|c|c|}
\hline & \multirow{2}{*}{ Total score } & \multirow{2}{*}{$\%$ score } & \multicolumn{2}{|c|}{ Negative beliefs $(<50 \%)$} & \multicolumn{2}{|c|}{ Positive beliefs ( $\geq 50 \%)$} \\
\hline & & & No. & $\%$ & No. & $\%$ \\
\hline $\begin{array}{l}\text { Beliefs about the perceived benefits, severity and } \\
\text { barriers to take PAP test to reduce risk of cervical cancer }\end{array}$ & $2.52 \pm 0.16$ & $50.73 \pm 5.21$ & 369 & 36.9 & 631 & 63.1 \\
\hline $\begin{array}{l}\text { Beliefs about Perceived susceptibility to acquire cervical } \\
\text { cancer or to have an abnormal Pap test }\end{array}$ & $2.66 \pm 0.35$ & $55.28 \pm 11.57$ & 224 & 22.4 & 776 & 77.6 \\
\hline $\begin{array}{l}\text { Beliefs about cues to action that cause that women take } \\
\text { the Pap test }\end{array}$ & $2.34 \pm 0.49$ & $44.70 \pm 16.48$ & 642 & 64.2 & 358 & 35.8 \\
\hline
\end{tabular}

In relation to table (9), it was noticed that more than three quarters $(77.6 \%)$ of the studied subjects had positive beliefs about Perceived susceptibility to acquire cervical cancer or to have an abnormal Pap test and about two thirds (63.1\%) had positive beliefs about the perceived benefits, severity and barriers to take PAP test to reduce risk of cervical cancer. While beliefs about cues to action that cause that women take the Pap test, about two thirds (64.2\%) had negative attitude. 
Table 10. Relation between socio-demographic data and total score of knowledge.

\begin{tabular}{|c|c|c|c|c|c|c|c|c|}
\hline & \multicolumn{6}{|c|}{ Knowledge } & \multirow{3}{*}{$\chi^{2}$} & \multirow{3}{*}{$\mathbf{p}$} \\
\hline & \multicolumn{2}{|c|}{ Low $<33.3 \%(n=842)$} & \multicolumn{2}{|c|}{ Moderate 33.3-66.6\% $(n=123)$} & \multicolumn{2}{|c|}{ High $>66.6 \%(n=35)$} & & \\
\hline & No. & $\%$ & No. & $\%$ & No. & $\%$ & & \\
\hline \multicolumn{9}{|l|}{ Age } \\
\hline Less than 20 years & 234 & 27.8 & 23 & 18.7 & 23 & 65.7 & \multirow{5}{*}{$62.504^{*}$} & \multirow{5}{*}{${ }^{\mathrm{MC}} \mathrm{P}=<0.001^{*}$} \\
\hline From 20 to less than 30 years & 511 & 60.7 & 63 & 51.2 & 12 & 34.3 & & \\
\hline From 30 to less than 40 years & 73 & 8.7 & 37 & 30.1 & 0 & 0.0 & & \\
\hline From 40 to less than 50 years & 14 & 1.7 & 0 & 0.0 & 0 & 0.0 & & \\
\hline 50 and more & 10 & 1.2 & 0 & 0.0 & 0 & 0.0 & & \\
\hline \multicolumn{7}{|l|}{ Marital Status } & \multirow{6}{*}{$17.369^{*}$} & \multirow{6}{*}{$0.005^{*}$} \\
\hline Married & 623 & 74.0 & 93 & 75.6 & 35 & 100.0 & & \\
\hline Divorced & 161 & 19.1 & 27 & 22.0 & 0 & 0.0 & & \\
\hline Single & 48 & 5.7 & 3 & 2.4 & 0 & 0.0 & & \\
\hline Widow & 10 & 1.2 & 0 & 0.0 & 0 & 0.0 & & \\
\hline \multicolumn{7}{|l|}{ Level of education } & & \\
\hline Illiterate & 113 & 13.4 & 9 & 7.3 & 0 & 0.0 & \multirow{6}{*}{$259.428^{*}$} & \multirow{5}{*}{${ }^{\mathrm{MC}} \mathrm{P}=<0.001^{\circ}$} \\
\hline Read and write & 118 & 14.0 & 9 & 7.3 & 0 & 0.0 & & \\
\hline Primary education & 252 & 29.9 & 12 & 9.8 & 0 & 0.0 & & \\
\hline Secondary education & 217 & 25.8 & 7 & 5.7 & 0 & 0.0 & & \\
\hline University or higher & 142 & 16.9 & 86 & 69.9 & 35 & 100.0 & & \\
\hline \multicolumn{7}{|l|}{ Number of children } & & \multirow{6}{*}{${ }^{\mathrm{MC}} \mathrm{P}=<0.001^{*}$} \\
\hline No & 643 & 76.4 & 50 & 40.7 & 1 & 2.9 & \multirow{6}{*}{$236.977^{*}$} & \\
\hline one child & 59 & 7.0 & 37 & 30.1 & 0 & 0.0 & & \\
\hline 2 or 3 children & 70 & 8.3 & 36 & 29.3 & 34 & 97.1 & & \\
\hline 4 or 5 children & 68 & 8.1 & 0 & 0.0 & 0 & 0.0 & & \\
\hline 6 or more children & 2 & 0.2 & 0 & 0.0 & 0 & 0.0 & & \\
\hline \multicolumn{7}{|l|}{ Duration of marriage } & & \multirow{7}{*}{$<0.001^{*}$} \\
\hline Unmarried & 48 & 5.7 & 3 & 2.4 & 0 & 0.0 & \multirow{6}{*}{$257.093^{*}$} & \\
\hline one year & 179 & 21.3 & 5 & 4.1 & 1 & 2.9 & & \\
\hline $2-3$ years & 98 & 11.6 & 39 & 31.7 & 0 & 0.0 & & \\
\hline 3 to less than 6 years & 80 & 9.5 & 20 & 16.3 & 27 & 77.1 & & \\
\hline 6 to less than 10 years & 177 & 21.0 & 55 & 44.7 & 7 & 20.0 & & \\
\hline More than 10 years & 260 & 30.9 & 1 & 0.8 & 0 & 0.0 & & \\
\hline
\end{tabular}

$\chi^{2}$ : Chi square test

MC: Monte Carlo for Chi square test

*: Statistically significant at $p \leq 0.05$

Knowledge of cervical cancer and Pap test was high (65.7\%) among subjects with younger age (less than 20 years), who married $(100 \%)$ and duration of marriage between 3 to less than $6(77.1 \%)$, had higher education $(100 \%)$ and had 2 or 3 children $(97.1 \%)$. The difference was statistically significant at $\mathrm{p} \leq 0.05$. Knowledge of cervical cancer and Pap test was lowest among women with primary education, had no children. Table (10)

\section{Discussion}

Cervical cancer is a preventable disease, and a key aspect of its prevention is the detection of the premalignant lesion by cervical screening [31]. The major findings of the present study showed that $88.7 \%$ of the respondents were not known of the cervical screening (Pap smear), however, only 13.3\% had known the test. The major drawback of this study is the high percentage of respondents, their education ranged between illiterate, read and write, primary or secondary education, which is usually expected in a typical population of a developing country. In contrast knowledge of cervical cancer and Pap test was high (65.7\%) among women with high education, this result congruence with result of Roberts et al. (2004), who found a positive relationship between the education and level of awareness on Pap smear among respondents [32].

In this study, $80.1 \%$ of the women were not know of HPV as a risk factor for cervical cancer. This result in line with Shin-Y L. (2015) conducted a study in Chicago in a sample consisting of 159 Korean-American women, 40-69 years of age. $26 \%$ of the respondents had never heard of the Pap smear test. Only $34 \%$ of respondents reported having had a Pap smear for screening, while another $20.8 \%$ reported having had a Pap smear due to health problem. The most frequently cited reason for not having had a Pap smear was not known it [33].

Using HBM constructs as a framework, our findings suggested that, although three-thirds (63.1\%) of Egyptian women had positive beliefs about perceived benefits, severity and barriers to take PAP test to reduce risk of cervical cancer these beliefs do not translate into the action of getting a Pap test because $64.2 \%$ had negative beliefs about cues to actions. This result in line with result of Tanner S. (2010), who found that higher levels of perceived severity of cervical cancer were associated with increased odds of having had a Pap screening [34]. The inconsistency of the association between perceived severity and cervical cancer screening may be due, in part, to the poor knowledge about cervical cancer and its screening tests. 
Also in the current study more than third of studied subjects $(42.9 \%)$ believed that cervical cancer can be cured easily if detected early this come in the same line with Zakia et al.(2013), who found that more than three quarters of the participants perceived that Pap smear is beneficial. (80.7\%), and having a test is valuable $(86.3 \%)$ and will give them a sense of control [35]. Also, Zakia et al (2013), added that, $90.6 \%$ has perceived that cervical cancer got more chance of cure and it is worth putting up with the treatment if any abnormal results are detected early. While the current study only $42.9 \%$ believed that cervical cancer can be cured easily if detected early. This in line with Grace et al 2013, who stated that about $50 \%$ of the participants believed that Pap tests are the best way to detect cervical cancer, cervical cancer can be easily treated if detected early, and a Pap test is important for staying healthy $[35,36]$.

Indeed, in our study, $77.9 \%$ disagree that they can die from cervical cancer and $62.1 \%$ of studied subjects disagree that Pap test decreases the chances of dying from cervical cancer. Also, $62.3 \%$ not have history of cervical cancer in their families. So, it is very unlikely to get Pap test. Low perceived risks were demonstrated the importance of educating Egyptian women about the risk for cervical cancer in order to increase their awareness. This result contradict with Grace et al (2013), who said that approximately one-third of women agreed with the statement: "Women having cervical cancer will die from it," [25].

Egyptian women in our study perceived significant barriers regarding access to health care. About one half of the participants expressed concerns about not had information and prefer to getting a Pap test, but the majority disagree that money or time act as a barrier, in contrast, these concerns were noted among Vietnamese American women [36]. Also, these factors which have already been reported in other studies [37, $38,39,40]$. In our study, the most frequently perceived cultural barriers to obtaining Pap tests were being uncomfortable with having a test performed by a male doctor but prefer female doctor $(46.9 \%)$, disagree not needing a test when feeling well $(61.2 \%)$, believing a test will be painful or unpleasant $(31.7 \%)$, and believing a Pap test is embarrassing (30.1\%). The belief that it is unnecessary to have a Pap test when one feels well is consistent with cultural beliefs that healthcare is a service that one seeks for specific, manifested complaints and symptoms [41]. With the exception of one study [42]. modesty is frequently cited as a barrier in accessing cervical cancer screening programs among Asian American women, including Vietnamese Americans [38, 43, 44].

These findings highlight the need to address these psychosocial concerns through education programs. While most such education programs only focus on women themselves, we believe husbands, and other family members should be involved in this collective effort. Their inclusion and comments were critical in providing recommendations for the design of educational and awareness campaigns for this community. Using a theoretical framework of HBM provides a close examination of Egyptian women's cultural beliefs and how these beliefs may be associated with cervical cancer screening behavior.

\section{Conclusion}

The present study concluded that inefficient utilization of cervical cancer screening had been affected by poor knowledge, and negative beliefs related to cervical cancer and its screening test. Considerable numbers of the studied subjects had positive beliefs about Perceived susceptibility to acquire cervical cancer or to have an abnormal Pap test and perceived benefits, severity and barriers to take PAP test to reduce risk of cervical cancer. Also, large numbers had negative believes about cues to action that cause that women take the Pap test.

\section{Recommendations}

Development of effective intervention programs strategies for Egyptian women and identify those women who are most at risk for cervical cancer and would benefit from intervention programs to increase cervical cancer screening rates. Health care providers must have a better understanding not only of the direct risk factors for cervical cancer, but also of the cognitive, emotional, and environmental aspects that might influence women's decision to participate actively in preventive screening programs.

\section{References}

[1] GLOBOCAN Cancer Fact Sheets: Cervical cancer - iarc. Estimated Incidence, Mortality and Prevalence Worldwide in 2012 Section of Cancer Surveillance (2016).

[2] Jimoh AS, Abdul IF. A review of one hundred and three (103) histologically confirmed cases of carcinoma of the cervix at the University of Ilorin Teaching Hospital Nigeria. Niger Med Pract. 2004; 45: 55-60.

[3] Egypt Human ICO Information Centre on HPV and Cancer. Fact Sheet (Feb 4, 2016). Papillomavirus and Related Cancers

[4] Adefuye PO. Knowledge and practice of cervical cancer screening among female professional health workers in a suburban district of Nigeria. Niger Med Pract. 2006; 50(1): 19-22.

[5] Bosch FX, Lorincz AT, Munoz N, Meijer CJ, Shah KV. The causal relation between human papillomavirus and cervical cancer. J Clin Pathol. 2002; 55: 244-265.

[6] Muñoz N, Bosch FX, Sanjosé S. The causal link between human papillomavirus and invasive cervical cancer: a population-based case-control study. Int J cancer. 2006; 119(5): 1108-1124.

[7] Schiller JT, Castellsagu X, Villa LL, Hildesheim A. An update of prophylactic human papillomavirus L1 virus-like particle vaccine clinical trial results. Vaccine. 2008; 26 (Suppl 10): K53-K61.

[8] Redmond O’Neal (2009) Cancer-stricken Farrah Fawcett weighs 86 pounds: Redmond O'Neal.www.thaindian.com/.../cancer-stricken-farrah-fawcettweighs-86-pounds-redmond-oneal_100181396.htmlUSA 
[9] Giuntoli RL, Bristow RE. Cervical cancer. In: Gibbs RS, Karlan BY, Haney AF, Nygaard I, editors. Danfoth's Obstetrics and Gynecology. 10th ed. Philadelphia: Lippincott Williams \& Wilkins, 2008: 971.

[10] Miller D, Riddell L, Franks AS, Ceballos K, Ehlen T, Kan L, et al. Screening for cancer of the cervix-anoffice manual for health professionals. British Columbia cancer agency. 2010.

[11] Bergstrom R, Adami HO. Trends in cancer of the cervix uteri in sweden following cytological screening. Br J Cancer, 1999; 81(1): 159-166.

[12] Cain JM, Howett MK. Preventing cervical cancer. Science, 2000; 288(5472): 1753-1755.

[13] Orbell S, Crombe I, Johnston G. Social cognitionand social structure in the prediction of cervical screening uptake. Br J Health Psych, 1996;1:35-50

[14] Whiteheada D, Russell G. How effective are heal the ducation programmes-resistance, reactance, rationality and risk? Recommendations for effective practice. Int J Nurs Stud 2004; 41: 163-72.

[15] Becker MH. The health belief model and personalhealth behavior. Health Education. Monograph, 1974; 2.Gakidou, E., Nordhagen, S., Obermeyer, Z. (2008).Coverage of Cervical Cancer Screening in 57 Countries: Low Average Levels and Large Inequalities. PLoS Medicine, Vol. 5, No. 6, (June 2008), e132.

[16] Ben-Natan, M., \& Adir, O. (2009). Screening for cervical cancer among Israeli women. International Nursing Review, Vol. 56, No.4, (Dec 2009), pp.433-441.

[17] Champion V.L., \& Skinner C.S. (2008). The Health belief model, In: Health behavior and health education, Glanz K, Rimer B. K, \& Viswanath, K pp45-66.

[18] Lee, M. C. (2000) Knowledge, barriers and motivators related to cervical cancer screening among Korean-American women: a focus group approach. Cancer Nursing, Vol. 23, No. 3 (June 2000), pp.168-175.

[19] Becker MH. Thorofare, NJ: Slack; 1974. The health belief model and personal health behavior.

[20] Rosenstock IM. Strecher VJ. Becker MH. Social learning theory and the health belief model. Health Educ Q. 1988; 15: $175-83$

[21] .Guvenc G. Akyuz A. Ikel CH. Health belief model scale for cervical cancer and Pap smear test: Psychometric testing. J Adv Nurs. 2011; 67: 428-437. [PubMed]

[22] Holroyd W, Twinn, Adab P (2004). Social-cultural influences on Chinese women's attendance for cervical screening. J Adv Nursing, 46, 42-52.

[23] Jandorf L, Bursac Z, Pulley L, et al (2008). Breast and cervical cancer screening among Latinas attending culturally specific.

[24] Hacihasanoğlu R, Gozum S (2008). The effect of training on the knowledge levels and beliefs regarding breast selfexamination on women attending a public education centre. Eur J Oncol Nursing, 12, 58-64.

[25] Grace X., Wanzhen Gao, Carolyn Y. Fang, Yin Tan, Ziding Feng, Shaokui Ge, and Joseph An Nguyen J Womens Health (Larchmt). 2013 Mar; 22(3): 276-288. Health Beliefs
Associated with Cervical Cancer Screening Among Vietnamese Americans.

[26] Bandura, A. (1986). The explanatory and predictive scope of self-efficacy theory. Journal of Clinical and Social Psychology, 4, 359-373.

[27] Champion, V. L. (1984). Instrument development for health belief model constructs, Advances in Nursing Science, 6, 7385 .

[28] Champion VL (1993). Instrument refinement for breast cancer screening behaviors. Nursing Res, 42, 139-43.

[29] Ackerson K, Gretebeck K (2007). Factors influencing cancer screening practices of underserved women. J Am Acad Nurse Pract, 19, 591-601.

[30] Akyüz A, Güvenç G, Yavan T, et al (2006). Kadınların Pap smearyaptırma durumları ile bunu etkileyen faktörlerin belirlenmesi. [Determining the women's to have Pap smear test and factors affecting to obtain Pap smear test]. Gulhane Med J, 48, 25-9.

[31] Khalid H., Attitudes, knowledge, and practices in relation to cervical cancer and its screening among women in Saudi Arabia. Saudi Med J, 30(9), 2009 1208-12.

[32] Roberts AA, Ayankogbe OO, Osisanya TF, Bamgbala AO, Ajekigbe AT, Olatunji BS. Knowledge of cervical cancers risk factors among refugee women in Oru camp. Nigerian Medical Practitioner 2004; 46: 67-70.

[33] Shin-Y L. Cultural Factors Associated with Breast and Cervical Cancer Screening in Korean American Women in the US: An Integrative Literature Review. Asian nursing research 2015; 9: Pages 81-90.

[34] Tanner-Smith EE. Brown TN. Evaluating the health belief model: A critical review of studies predicting mammographic and pap screening. Soc Theory Health. 2010; 8: 95-125.

[35] Zakia Metwali, Fatima Al Kindi, Sawsan Shanbleh, Sarah Al Akshar, Fadi Sarhan. (Evaluating awareness and screening of cervical cancer among women in Sharjah, United Arab Emirates) IOSR Journal Of Pharmacy; 5: (February 2015), PP. 57-64.

[36] Ho V. Yamal JM. Atkinson EN. Predictors of breast and cervical screening in Vietnamese women in Harris County, Houston, Texas. Cancer Nurs. 2005; 28: 119-129. [Pub Med]

[37] Wang JH. Sheppard VB. Schwartz MD. Liang W. Mandelblatt JS. Disparities in cervical cancer screening between Asian American and non-Hispanic white women. Cancer Epidemiol Biomarkers Prev. 2008; 17: 1968-1973. [PubMed]

[38] Fang CY. Ma GX. Tan Y. Overcoming barriers to cervical cancer screening among Asian American women. N A J Med Sci. 2011; 4: 77-83. [PMC free article] [Pub Med]

[39] Ma G. Toubbeh J. Wang M. Shive S. Cooper L. Pham A. Factors associated with cervical cancer screening compliance and noncompliance among Chinese, Korean, Vietnamese, and Cambodian women. J Natl Med Assoc. 2009; 101: 541-51. [Pub Med]

[40] Gor B. Chilton J. Camingue P. Hajek R. Young Asian Americans' knowledge and perceptions of cervical cancer and the human papillomavirus. J Immigr Minor Health. 2011; 13: 81-86. [Pub Med] 
[41] Lee MC. Knowledge, barriers, and motivators related to cervical cancer screening among Korean-American women: A focus group approach. Cancer Nurs. 2000; 23: 168-75. [Pub Med]

[42] Taylor VM. Yasui Y. Burke N, et al. Pap testing adherence among Vietnamese American women. Cancer Epidemiol Biomarkers Prev. 2004; 13: 613-619. [PubMed]
[43] Lee-Lin F. Pett M. Menon U, et al. Cervical cancer beliefs and pap test screening practices among Chinese American immigrants. Oncol Nurs Forum. 2007; 34: 1203-1209. [Pub Med]

[44] Tanner-Smith EE, Brown TN. Evaluating the health belief model: A critical review of studies predicting mammographic and pap screening. Soc Theory Health 2010; 8: 95-125.] 